\title{
Bilateral Lesions of the Habenula Induce Attentional Disturbances in Rats
}

\author{
Lucas Lecourtier ${ }^{1,2}$ and Peter H Kelly*,1 \\ 'Psychiatry Program, Neuroscience Research, Novartis Institutes for BioMedical Research, Novartis Pharma AG, Basel, Switzerland; ${ }^{2}$ CNRS UMR \\ 5106, Laboratoire de Neurosciences Cognitives, Université de Bordeaux I, Avenue des Facultés, 33405 Talence Cedex, France
}

\begin{abstract}
The habenular nuclear complex is a major influence on brainstem cell groups that influence attention, but its role in attentional performance has not previously been explored. The present study investigated how habenula lesions affect attentional function as assessed by the 5-choice serial reaction time task (5-CSRTT) in male Lister-Hooded rats. Rats were pretrained in the 5-CSRTT before receiving discrete bilateral lesions of the habenula or a sham procedure. In test sessions immediately following recovery from surgery, lesioned rats showed a marked increase in premature responding. Over the course of testing this increase of premature responding declined in magnitude. In contrast, choice accuracy showed no impairment during the earliest postsurgery test sessions but progressively deteriorated over the course of testing. These opposite time courses strongly imply that different mechanisms mediate these two effects of the habenula lesion. Differential effects of drug treatment on these effects further supported this view. Thus, D-amphetamine ( $0.2 \mathrm{mg} /$ $\mathrm{kg}$ s.c.) increased premature responding without affecting choice accuracy. On the other hand, haloperidol (0.0 I- $0.03 \mathrm{mg} / \mathrm{kg}$ i.p.) decreased premature responding without significantly affecting choice accuracy. The results are consistent with the view that elevated premature responding in habenula-lesioned animals is mediated by increased dopaminergic activity, whereas impaired choice accuracy is not. Implications of these findings for the hypothesis that habenula dysfunction is involved in cognitive symptoms of schizophrenia are discussed.
\end{abstract}

Neuropsychopharmacology (2005) 30, 484-496, advance online publication, 24 November 2004; doi: I 0. I038/sj.npp. I 300595

Keywords: habenula; lesions; attention; dopamine; amphetamine; haloperidol

\section{INTRODUCTION}

The anatomical connections of the habenular nuclear complex indicate that it is a link between forebrain areas and midbrain cell groups such as the locus coeruleus, raphé nuclei, substantia nigra, and ventral tegmentum that project widely to most brain regions (Sutherland, 1982). Consistent with such widespread influences, it is implicated in diverse functions including anxiety (Murphy et al, 1996; Kurumaji et al, 2003), stress (Amat et al, 2001; Sica et al, 2000), analgesia (Cohen and Melzack, 1993), maternal behavior (Corodimas et al, 1993; Felton et al, 1998), sleep (Haun et al, 1992; Valjakka et al, 1998), behavioral flexibility (Thornton and Evans, 1982), reinforcement (Sutherland and Nakajima, 1981), and spatial memory (Lecourtier et al, 2004). The recent description of 15 subnuclei within the habenular complex (Andres et al, 1999; Geisler et al, 2003) should

\footnotetext{
*Correspondence: Dr PH Kelly, Psychiatry Program, Neuroscience Research, Novartis Institutes for BioMedical Research, WSJ-386.262, Novartis Pharma AG, Basel CH-4002, Switzerland, Tel: +4I 61324 4367, Fax: + 4I 6I 324 38 I I, E-mail: peter.kelly@pharma.novartis.com Received 18 May 2004; revised 27 August 2004; accepted 17 September 2004

Online publication: 22 September 2004 at http://www.acnp.org/citations/ Npp09220404023।/default.pdf
}

eventually be of great assistance for future research aimed at elucidating the particular circuits that mediate these specific behaviors.

Recently, a number of findings have begun to suggest that pathology of the habenula could be involved in some of the symptoms of schizophrenia. Thus, Sandyk (1992) reported that large calcifications of the habenula are more frequent in schizophrenia patients. The epithalamus as a whole, comprising habenula plus the pineal organ, has also been shown to exhibit greater calcification in schizophrenia patients than controls (Caputo et al, 1998). A role of habenula pathology in schizophrenia has been proposed by Ellison (1994) based on several lines of evidence, particularly the findings that chronic administration of amphetamine or cocaine to rats causes degeneration in the fasciculus retroflexus output pathway of the habenula, and in man can elicit a schizophrenia-like state. Moreover, the habenula can be expected to be particularly affected by certain genetic polymorphisms that are linked to schizophrenia. For example, an association of schizophrenia with genetic variants of the neuregulin 1 (NRG1) gene has been found in several different populations (Stefansson et al, 2002, 2003; Williams et al, 2003, Yang et al, 2003; Corfas et al, 2004). Such variants should particularly affect habenula function since the medial habenula is one of the brain areas 
showing the highest level of expression of erbB4, a major receptor for NRG1 in the CNS (Steiner et al, 1999). Several hypotheses of how habenula pathology could generate symptoms of schizophrenia have been proposed (Sandyk, 1991; Ellison, 1994; Kelly, 1998). If as suggested, habenula pathology does contribute to the symptoms of schizophrenia, then habenula lesions in experimental animals should produce behavioral changes resembling those in schizophrenia. Recently, we began to examine this prediction by investigating the effects of habenula lesions on functions that are impaired in schizophrenia, namely memory performance, prepulse inhibition (PPI), and social interaction. Our results showed that habenula-lesioned rats exhibited a deficit in spatial learning in the Morris water maze, but no change of PPI or of social exploration, implicating habenula pathology particularly in memory impairment (Lecourtier et al, 2004).

Another frequent neurocognitive abnormality in schizophrenia, noted already by Kraepelin (1919/1971) and Bleuler (1911/1950), is disturbed attention. The concept of attention nowadays encompasses several aspects, such as sustained attention or the continuous allocation of sensory processing resources for the detection of rare events, divided attention, to monitor and respond to several different sensory channels, and selective attention, the ability to focus sensory processing resources on certain types of stimuli, while ignoring others (Robbins, 2002). Introspective reports from patients with schizophrenia (McGhie and Chapman, 1961), such as 'I can't concentrate. It's diversion of attention that troubles me', indicated problems in selective and sustained attention. Quantitative studies of sustained attention have mostly used the continuous performance task, in which the subject must respond to a target stimulus whenever it appears in a rapid succession of nontarget stimuli. In this task, and versions of it that either increase the working memory load by requiring a sequence of stimuli to be detected or increase the sensory processing burden by degrading the stimuli, numerous studies have shown that patients with schizophrenia have, on average, impaired performance (Orzack and Kornetsky, 1966; Nestor and O'Donnell, 1998; Cadenhead and Braff, 2000). Such deficits are indicated not only by hit rate and errors, which are influenced by response bias, but also by changes in the information processing sensitivity index, $d^{\prime}$, which is independent of response bias. A recent meta-analysis has shown that worse performance by patients with schizophrenia in this task, assessed by $d^{\prime}$, correlates with negative symptoms (Nieuwenstein et al, 2001). Similar effects in a substantial proportion of nonaffected siblings of patients with schizophrenia (Finkelstein et al, 1997; Chen and Faraone, 2000) suggests that attention deficit may be a marker of genetic susceptibility to schizophrenia.

To further test the hypothesis that habenula lesions in experimental animals should produce behavioral changes resembling those in schizophrenia, the present studies examine if habenula lesions modify performance in a wellstudied attention task, the 5-choice serial reaction time task (5-CSRTT) in which a rat must attend to one wall of a Skinner box containing five recesses. The rat must quickly respond to a brief light stimulus that appears randomly in one of these recesses in order to obtain reinforcement (Carli et al, 1983; Robbins, 2002). This task allows changes in different aspects of attentional performance such as choice accuracy, premature responding, and perseverative responding to be determined in the same test. Moreover, a considerable amount has been discovered about the physiology and pharmacology of this task (Robbins, 2002), so that the results obtained may be integrated with this knowledge.

\section{MATERIALS AND METHODS}

\section{Animals}

The experiments were carried out with 24 male ListerHooded rats (Iffa Credo, France) housed in pairs in Macrolon cages $\left(42 \times 26 \times 15 \mathrm{~cm}^{3}\right)$ in a temperature-regulated $\left(22 \pm 2^{\circ} \mathrm{C}\right)$ animal room on a $12 \mathrm{~h}$ light/dark cycle (lights on at 0600). Drinking water was available ad libitum. Rats performed the test daily, except that during the prelesion training they were not run at weekends. On testing days, the animals received 15-16 g of food (Nafag 890 Rat Chow, Provimi Kliba, Switzerland) per day per rat, given immediately after the test (equally distributed in two opposite corners of the cage). When no tests were performed at the weekend, lab chow was available ad libitum from Friday evening until 1100 on Sunday morning. The experiments were approved by the Cantonal Veterinary Authority of the City of Basel. Animals were acclimatized to the animal quarters for at least a week before starting the experiments, which took place during the light phase.

\section{Surgical Procedures}

Lesions of the habenula or sham operations were performed as previously described (Lecourtier et al, 2004), except that inhalation anesthesia was used. The animals were anesthetized with isoflurane (Forene ${ }^{\circledR}$, Abbott, USA) and placed in a stereotaxic frame with the tooth bar higher than the ear bars to correspond to the stereotaxic atlas of Pellegrino et al (1979). Since this atlas is based on rats weighing between 250 and $350 \mathrm{~g}$, and as the weights of our animals at the time of operation were above this range, the elevation of the tooth bar above ear bars was adjusted according to a formula (Whishaw et al, 1977), which maintains the skull at the correct angle for the stereotaxic atlas. Bilateral electrolytic lesion of the habenular nuclei (lateral plus medial) was performed with stainless-steel electrodes (00 gauge insect pins, Emil Arlt, Vienna, Austria; insulated except at the tip) by passage of a DC current of $1 \mathrm{~mA}$ for $15 \mathrm{~s}$ through the anode in the brain and a saline-soaked cotton swab on the tail as cathode. Constant current was provided by a Heinzinger LNG 350-03 power supply through a $100 \mathrm{k} \Omega$ series resistor, and was monitored by a current meter. The electrodes were inserted at a $10^{\circ}$ angle in order to avoid the saggital sinus. Thus, to position the electrode tip at the point AP $-2.2 \mathrm{~mm}, \mathrm{ML} 0.6 \mathrm{~mm}, 4.8 \mathrm{~mm}$ below dura (Pellegrino et al, 1979), the 'lateral' displacement of the electrode carrier (still at an angle of $10^{\circ}$ to the vertical) after positioning it at the midpoint of the saggital sinus at the desired AP coordinate was $1.5 \mathrm{~mm}$, and the depth displacement of the electrode was $4.9 \mathrm{~mm}$ along the $10^{\circ}$ angle track. For the sham-operated animals, the electrode was inserted at the same coordinates for the same amount of time, but no 
current was passed. After the animals awoke, they were injected $(1 \mathrm{ml} / \mathrm{kg}$ s.c.) with an analgesic $(0.3 \mathrm{mg} / \mathrm{ml} \mathrm{Temge-}$ sic $^{\circledR}$, Essex Chemie AG, Luzern, Switzerland) and returned to their home cage where they were allowed to recover for 8 days.

\section{Apparatus}

Six 9-CSRTT chambers (Med Associates, Vermont, USA) were used during this study. Each rat was run in the same chamber during the entire series of experiments. Five of the nine nose-poke recesses were used (numbers 1, 3, 5, 7, and 9), the others were blocked by screwed-on metal plates. The chambers were equipped with a dim house light, a stimulus light inside each recess and a pellet dispenser in the wall opposite to the stimulus recesses. Nose-pokes into the stimulus light recesses or into the food pellet well were registered by photocell beam assemblies. The chambers were housed in sound-insulated and ventilated enclosures.

\section{The 5-CSRTT}

The test was as originally described by Carli et al (1983). All experimental contingencies and collection of data were controlled by a computer program written in the MED-PC language (Med Associates, Vermont, USA). The test began by the switching on of the house light and delivery of a food pellet into the feeder. When the rat retrieved a pellet from the feeder, a 5-s intertrial interval (ITI) was initiated, followed by switching on a stimulus light in one of the stimulus recesses. If the animal nose-poked into the correct recess during the stimulus or within an immediately following limited hold period (see Table 1), a reward (45 mg Noyes pellet, Bilaney AG, Frankfurt, Germany) was delivered into the feeder. Throughout the experiment the parameters analyzed were the following:

Correct responses: A correct response was recorded when the first nose-poke after the stimulus onset within the time allowed (stimulus duration + limited hold) was into the recess where the stimulus appeared.

Incorrect responses: An incorrect response was recorded when the first nose-poke after the stimulus onset within the time allowed (stimulus duration + limited hold) was into a recess where the stimulus did not appear.

Response omissions: An omission was recorded when no recess was nose-poked within the time allowed (stimulus duration + limited hold).

Table I Stimulus Duration and Limited Hold Duration in the 5-CSRTT at Progressive Levels of Difficulty

\begin{tabular}{lcc}
\hline Levels & Stimulus duration (s) & Limited hold duration (s) \\
\hline 1 & 30 & 30 \\
2 & 15 & 15 \\
3 & 5 & 15 \\
4 & 2 & 10 \\
5 & 1 & 10 \\
6 & 0.5 & 5 \\
\hline
\end{tabular}

Premature responses: A premature response was recorded for every nose-poke response (ie into any stimulus recess) made in the ITI between the animal retrieving a pellet and the onset of a stimulus (ie responses made after initiating a trial but before the appearance of the stimulus).

Perseverative responses: Responses made after a correct or incorrect response in the same or any other recess before nose-poking the food-reward well.

Latency to collect the food pellet: The time from a correct response to nose-poking the food-reward well to collect the food pellet, averaged over the session.

Latency of correct responses: The time from onset of the stimulus light until a correct nose-poke response, averaged over the session.

Latency of incorrect responses: The time from onset of the stimulus light until an incorrect nose-poke response, averaged over the session.

Whereas correct responses were rewarded by delivery of a food pellet, incorrect responses were followed by a timeout (TO) when the house light was switched off until the rat nose-poked into the pellet feeder well, which ended the TO and started another 5-s ITI before stimulus presentation. Premature responses during the ITI caused a 5-s TO, during which any further premature responses reset the TO to the beginning. Moreover, if the animal made no nose-poke into any recess within the duration of the stimulus and limited hold, then this 'missed response' also initiated an unlimited TO, from which the only means of exit was a nose-poke into the food well.

Percent correct responses, the measure of choice accuracy, and percent omissions were calculated daily to determine if a rat should progress to a higher level of difficulty. Whenever a rat reached the criterion of at least $80 \%$ correct responses and $<20 \%$ omissions on two consecutive days, it was progressed to the next training level (see Table 1). Percent correct responses were calculated as correct responses/(correct responses + incorrect responses $) \times 100$. Percent omissions were calculated as response omissions/(correct responses + incorrect responses + response omissions) $\times 100$.

One test was given per day, lasting $30 \mathrm{~min}$ or 100 reinforcements, whichever came first. During each session, the stimulus light was presented approximately an equal number of times in each of the five holes, chosen randomly.

The animals were operated after at least 4 weeks at level 6 , and their allocation into the two surgery groups was conducted in a counterbalanced manner based on their preoperative baseline performance. Animals that did not reach level 6 were not included in the experimental analysis. However, so that each cage contained either two lesioned or two sham-operated animals that were treated identically, they were operated appropriately and performed the test daily, receiving the same drug treatment as their cage partners. In this way variability between cages, in terms of number of rats per cage and number of drug-treated rats per cage, was reduced.

\section{Preoperative Training}

Before starting training rats were food-deprived (15-16 g of rat chow per day) and allowed to eat the food pellets in their 
home cages for 2 days, in order to habituate them to this new food. On the next day, the rats were placed singly in the test chambers with three food pellets in the food well and each stimulus light recess, and allowed to explore the box and eat the pellets. The following day automatic training was initiated at the easiest level of difficulty, level 1 . Whenever an animal met on two consecutive days criteria of $>80 \%$ correct responses and $<20 \%$ omissions, as defined above, it was progressed on the following day to the next level of difficulty (see Table 1).

\section{Postoperative Evaluation}

The postoperative evaluation of the lesioned and shamoperated control animals was comprised of the following phases:

Phase 1: Baseline performance 9-20 days post-surgery. Postoperative testing began 9 days after surgery. Of 11 animals that received lesions four were excluded because of not satisfying the criteria of substantial bilateral damage to the medial and lateral habenula with only minimal damage to neighboring structures. The sham group was composed of nine rats. To assess the effect of the lesion on baseline performance shortly after lesion, the animals performed the task at level 6 once per day for 12 successive days.

Phase 2: Effect of D-amphetamine on task performance. To evaluate the response of the rats to an enhancement of dopaminergic transmission, a single dose of amphetamine $(0.2 \mathrm{mg} / \mathrm{kg}$ s.c., $30 \mathrm{~min}$ before the session) was administered to the animals in a crossover design that allowed sensitive within-subjects statistical comparisons. On the first day, every rat received a vehicle injection $(0.9 \% \mathrm{NaCl}, 1 \mathrm{ml} / \mathrm{kg}$ s.c., $30 \mathrm{~min}$ before the session) to accustom them to being injected. On the second day, half the animals (alternate animals) were given drug and half vehicle. On the third day, all rats received vehicle. On the fourth day, the animals that had previously received drug received vehicle, and those that had previously received vehicle received drug. The data collected in the tests of the second and the fourth day were used for statistical comparisons.

Phase 3: Baseline performance 41-52 days postsurgery. Following the amphetamine experiment, the animals were not tested for a week, after which they were returned to the baseline task and tested drug-free for a further 12 days.

Phase 4: Effect of haloperidol on task performance. On the day immediately following the previous phase, the animals were injected with vehicle ( $1 \%$ lactic acid ( $\mathrm{pH} 4.5)$ i.p., 30 min before the session), and on the following day all of them received an acute injection of haloperidol $(0.1 \mathrm{mg} / \mathrm{kg}$ in $1 \%$ lactic acid ( $\mathrm{pH} 4.5$ ) i.p., $30 \mathrm{~min}$ before the session). It was clear that after $0.1 \mathrm{mg} / \mathrm{kg}$ haloperidol most animals responded very little in this task. Therefore, the rats were returned to baseline drug-free for four consecutive days, and then were tested with two lower doses of haloperidol or vehicle in a Latin square design. The treatments were vehicle ( $1 \%$ lactic acid, $\mathrm{pH} 4.5)$ or haloperidol $(0.01$ and $0.03 \mathrm{mg} / \mathrm{kg})$. All treatments were administered i.p. $30 \mathrm{~min}$ before the session. Between treatment days, to allow elimination of drug, the animals performed the task after vehicle treatment during three consecutive days.
Phase 5: Baseline performance 77-84 days postsurgery. Following the haloperidol experiment, the animals were not tested for a week, after which they were returned to the baseline task and tested drug-free for a further 8 days.

\section{Drugs}

All solutions were prepared fresh on the day of use. D-amphetamine sulfate (Siegfried, Zofingen, Switzerland) was dissolved in $0.9 \% \mathrm{NaCl}$ and injected in a volume of $1 \mathrm{ml} / \mathrm{kg}$. Haloperidol (Sigma, St Louis, MO, USA) was dissolved in $1 \%$ lactic acid, brought to $\mathrm{pH} 4.5$ by addition of 1 and $0.1 \mathrm{M} \mathrm{NaOH}$, and injected in a volume of $1 \mathrm{ml} / \mathrm{kg}$. Vehicle-treated animals received the same volume of the corresponding vehicle.

\section{Assessment of the Lesions}

Lesions were verified histologically and by assessing neurochemically the reduction of choline acetyltransferase (ChAT) in the interpeduncular nucleus (IPN), the terminal region of the habenulo-interpeduncular tract. The animals were killed at the end of the experiments by decapitation, the brains were removed, placed on an ice-cold glass plate, and the IPN was quickly dissected out for assay of ChAT. The remaining brain was immediately frozen on a metal plate on dry ice for histological verification of the lesion.

To histologically verify the extent of the lesion, the brains were freeze-sectioned in a cryostat. Slices $(25 \mu \mathrm{m})$ were taken through the entire habenula, mounted on slides, and stained with Toluidine blue. Lesions of the habenula were considered acceptable when surrounding regions (ie dorsal hippocampus and thalamic nuclei: paraventricular, dorsomedial, lateral, and parafascicular) were spared. Four animals whose lesions did not meet these criteria were excluded from the study.

ChAT activity of the IPN was assayed by a slight modification of the method of Fonnum (1975), using $\left[{ }^{14} \mathrm{C}\right]$ acetyl coenzyme A (Amersham, UK) as acetyl donor. This activity provides an index of the lesion of the medial habenula, which contributes the majority of the cholinergic innervation of the IPN. The IPN was homogenized in icecold homogenizing buffer (10 mM EDTA ( $\mathrm{pH} 7.4$ ), containing $0.5 \%$ Triton $\mathrm{X}-100)$. A final dilution of $1: 400$ was made from which $5 \mu \mathrm{l}$ were added to $10 \mu \mathrm{l}$ of an incubation mix and the assay performed as described previously (Kelly and Moore, 1978).

\section{Statistics}

With concern to the postoperative drug-free performances, average values of the various performance parameters were calculated per rat for each of the three drug-free blocks of trials that comprised the phases 1, 3, and 5 described in the Materials and methods, and these were analyzed by twofactor ANOVA, with lesion group as one factor and trial block as a repeated factor. In the case of a significant effect of lesion group or a significant lesion group $\times$ session interaction, the data of the two groups in individual trial blocks were compared by one-way ANOVA to see when the differences occurred. Within the sham and lesion groups comparisons of the data from block 1 to that from later 
blocks were made by paired $t$-tests. Data from the amphetamine and haloperidol experiments were analyzed by ANOVA with drug treatment as a repeated factor to correspond to the use of crossover and Latin square designs in these experiments. In the case of a significant effect of lesion group or a significant lesion group $\times$ drug treatment interaction, the data of the two groups at individual dose levels were compared by one-way ANOVA. Within the sham and lesion groups, comparisons of individual doses to the vehicle control condition were made by paired $t$-tests. All statistical analyses were performed by means of the SYSTAT software package (Version 10.2, SPSS Inc., Chicago, IL, USA).

\section{RESULTS}

From the 24 rats at the beginning of the training session, four failed to reach the criterion and were not included in the statistical analysis. From the 11 lesioned animals, four did not have a satisfactory lesion and were also eliminated from the statistical analysis. Moreover, treatment with $0.1 \mathrm{mg} / \mathrm{kg}$ of haloperidol did not allow any analysis by ANOVA, as this dose markedly reduced responding, probably due to effects on the motor system, sham and lesioned animals making only $3.9 \pm 1.3$ and $3.4 \pm 1.5$ (mean \pm SEM) total responses, respectively. Otherwise, no data were excluded from analysis.

\section{Choice Accuracy}

Effects of bilateral habenula lesions on drug-free performance. Two-factor ANOVA showed a significant difference between groups $(\mathrm{F}(1,14)=5.27 ; p<0.05)$, a significant effect of trial block $(\mathrm{F}(2,28)=15.98 ; p<0.0001)$, and a significant interaction of these factors $(\mathrm{F}(2,28)=5.42 ; p<0.01)$. These results confirm statistically the conclusion (drawn from inspection of Figure 1) that lesioned animals performed less accurately than control animals, and that the difference between control and lesioned animals was greater as training progressed. In fact, in comparisons between the groups during the individual trial blocks, a significant difference between the control and lesion groups occurred only in the third block.

Effects of D-amphetamine treatment. There was no effect of lesion group on the percentage of correct responses $(\mathrm{F}(1,14)=2.4 ; p>0.1)$. Neither was there a significant effect of drug treatment $(\mathrm{F}(1,14)=0.007 ; p>0.1)$ nor any significant interaction of lesion group $\times$ drug treatment $(\mathrm{F}(1,14)=1.9 ; p>0.1)$ (Figure 2$)$.

Effects of haloperidol treatment. The results are shown in Figure 3. There was no significant effect of lesion group on the percentage of correct responses $(\mathrm{F}(1,14)=0.3 ; p>0.1)$. Neither was there a significant effect of drug treatment $(\mathrm{F}(2,28)=3.2 ; p>0.1)$, but the interaction of lesion group $\times$ drug treatment was significant $(\mathrm{F}(2,28)=3.8 ; p<0.05)$. Inspection of the data showed that the $0.03 \mathrm{mg} / \mathrm{kg}$ dose of haloperidol impaired choice accuracy in sham, but not lesioned animals. Post hoc comparison in the sham group between the $0.03 \mathrm{mg} / \mathrm{kg}$ dose of haloperidol and vehicle treatment showed a difference that was not quite significant (paired $t$-test, $p=0.055$ ), so this effect is currently best considered to be a strong tendency.

\section{Premature Responses}

Effects of bilateral habenula lesions on drug-free performance. Two-factor ANOVA showed significant effects of lesion group $(\mathrm{F}(1,14)=12.28 ; \quad p<0.005)$, trial block $(\mathrm{F}(2,28)=13.96 ; p<0.001)$, and a significant interaction of these factors $(\mathrm{F}(2,28)=4.73 ; p<0.05)$. These results are consistent with the conclusion that premature responses were increased in habenula-lesioned animals, and that, in contrast to the change in choice accuracy, this effect declined in magnitude over trial blocks (Figure 1).

Effects of D-amphetamine treatment. Two-factor ANOVA showed significant effects of lesion group $(\mathrm{F}(1,14)=11.69$; $p<0.01)$ and amphetamine treatment $(\mathrm{F}(1,14)=10.34$; $p<0.01)$, but no significant interaction of lesion group $\times$ drug treatment $(\mathrm{F}(1,14)=0.1 ; p>0.6)$. Thus, premature

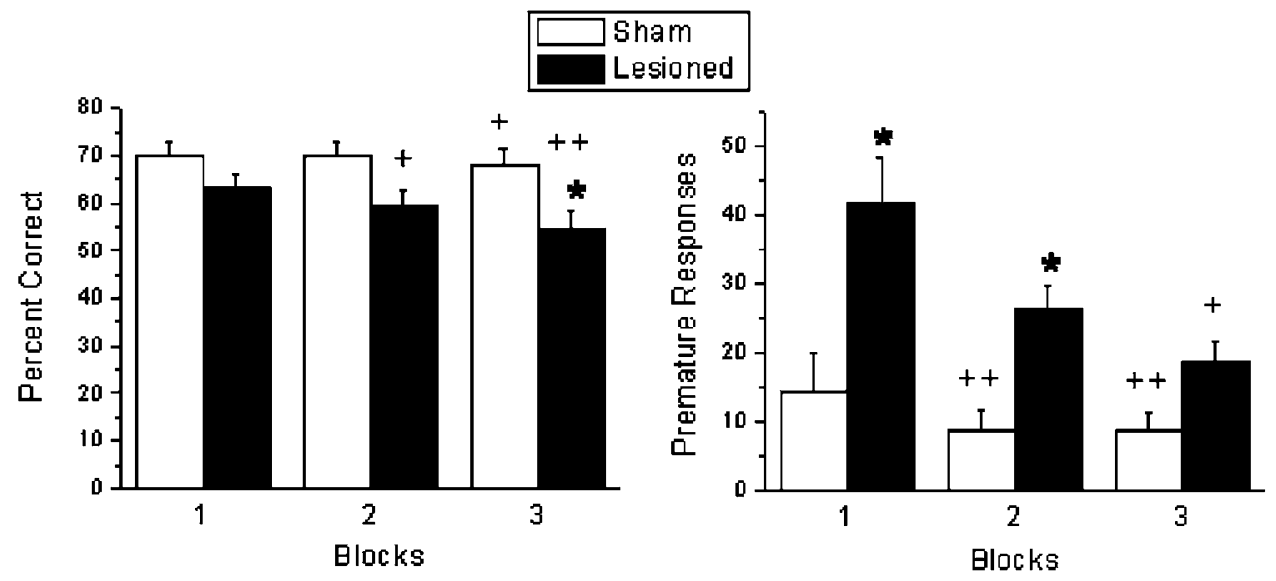

Figure I Impairments of choice accuracy and elevated premature responding in bilateral habenula-lesioned rats. Choice accuracy (left panel) and premature responses (right panel) are shown during blocks of drug-free performance on postoperative days 9-20 (block I), 4I-52 (block 2), and 77-84 (block 3). Columns and bars show the means \pm SEM of sham-operated $(n=9)$ and bilateral habenula-lesioned subjects $(n=7)$. * $p<0.05$ compared to the sham group at the same time point (one-factor ANOVA); ${ }^{+} p<0.05,{ }^{+}+p<0.01$ vs same group at block I (two-tailed paired t-test). 


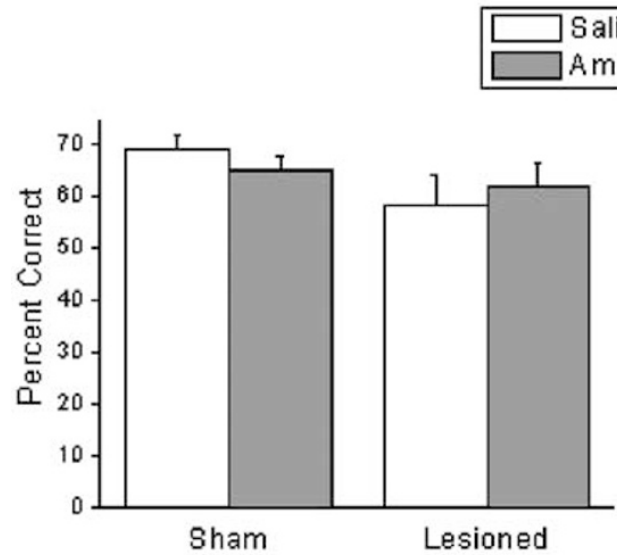

Saline

Amph $0.2 \mathrm{mg} / \mathrm{kg}$

Sham

Lesioned

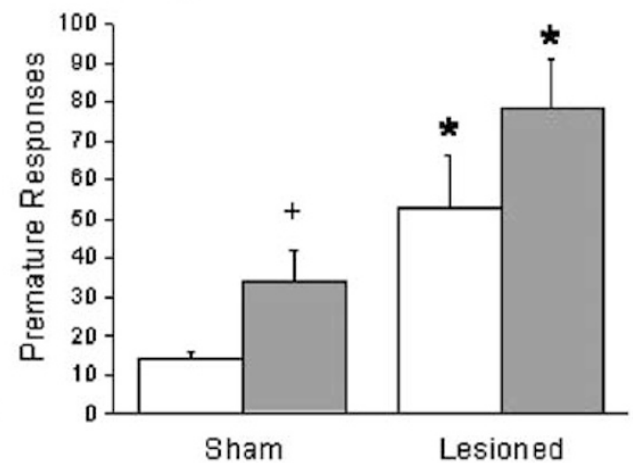

Figure 2 D-Amphetamine elevates premature responding in sham-operated and habenula-lesioned rats without influencing choice accuracy. Choice accuracy (left panel) and premature responses (right panel) are shown during sessions where the rats received saline or D-amphetamine (0.2 mg/kg s.c.) 30 min before testing. Columns and bars show the means \pm SEM of sham-operated $(n=9)$ and bilateral habenula-lesioned subjects $(n=7)$. $* 0<0.05$ compared to corresponding sham group data (one-factor AÑOVA); ${ }^{+} p<0.05$ vs same group saline condition (two-tailed paired $t$-test).

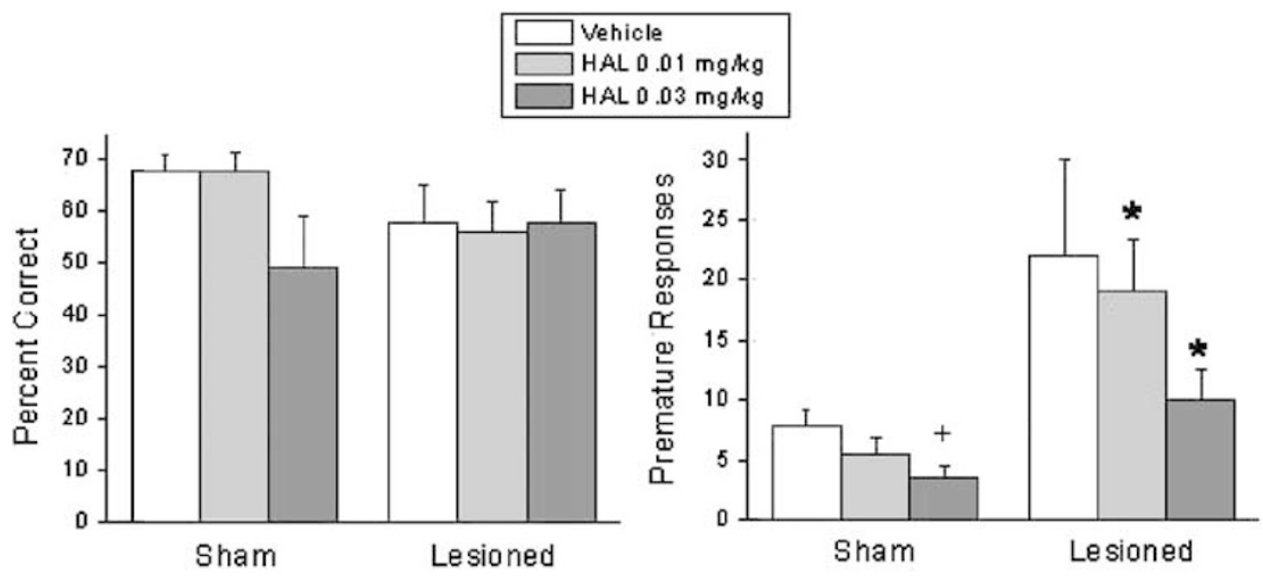

Figure 3 Haloperidol reduces premature responding in sham-operated and habenula-lesioned rats without influencing choice accuracy in lesioned rats. Choice accuracy (left panel) and premature responses (right panel) are shown during sessions where the rats received vehicle or haloperidol (0.0 I or $0.03 \mathrm{mg} / \mathrm{kg}$ i.p.) $30 \mathrm{~min}$ before testing. Columns and bars show the means \pm SEM of sham-operated $(n=9)$ and bilateral habenula-lesioned subjects $(n=7)$. ${ }^{*} p<0.05$ compared to the sham group after the same drug treatment (one-factor ANOVA); ${ }^{+} p<0.05$ vs same group saline condition (two-tailed paired t-test).

responses were higher in lesioned animals, and were increased by amphetamine (Figure 2).

Effects of haloperidol treatment. There was a significant effect of lesion group on the mean number of premature responses $(\mathrm{F}(1,14)=8.8 ; \quad p<0.05)$, and a significant effect of drug treatment $(\mathrm{F}(2,28)=4.4 ; p<0.05)$, but no significant interaction of lesion group $\times$ drug treatment $(\mathrm{F}(2,28)=1.1 ; p>0.1)$. These results confirm the impression from inspection of the data that premature responses were elevated in habenula-lesioned animals, and that haloperidol reduced the number of premature responses (Figure 3).

\section{Response Omissions}

Effects of bilateral habenula lesions on drug-free performance. Two-factor ANOVA of the percentage omissions showed a significant effect of trial block $(\mathrm{F}(2,28)=8.46$; $p<0.005)$, but no effect of lesion group $(\mathrm{F}(1,14)=1.09$; $p>0.1)$ and no interaction of these factors $(\mathrm{F}(2,28)=0.34$; $p>0.1$ ) (Table 2).

Effects of D-amphetamine treatment. The percentage of omitted responses was not affected by lesion group $(\mathrm{F}(1,14)=0.2 ; p>0.1)$. Neither was there any significant effect of drug treatment $(\mathrm{F}(1,14)=1.3 ; p>0.1)$ nor any significant interaction of lesion group $\times$ drug treatment $(\mathrm{F}(1,14)=1 ; p>0.1)($ Table 3$)$.

Effects of haloperidol treatment. There was a significant effect of lesion group on the percentage of omitted responses $(\mathrm{F}(1,14)=4.63 ; p<0.05)$, as well as a significant effect of drug treatment $(\mathrm{F}(2,28)=11.6 ; p<0.01)$, but there was no significant interaction of lesion group $\times$ drug treatment $(\mathrm{F}(2,28)=2.03 ; p>0.1)($ Table 4$)$. 
Table 2 Performance Parameters of Sham Control and Habenula-Lesioned Animals during Drug-Free Phases

\begin{tabular}{|c|c|c|c|c|c|c|}
\hline \multirow[b]{2}{*}{ Parameters } & \multicolumn{2}{|c|}{ Block I } & \multicolumn{2}{|c|}{ Block 2} & \multicolumn{2}{|c|}{ Block 3} \\
\hline & Sham & Lesioned & Sham & Lesioned & Sham & Lesioned \\
\hline Perseverative responses & $22.6 \pm 2.5$ & $22.7 \pm 2.8$ & $19.7 \pm 2.4$ & $19.7 \pm 3.4$ & $16.8 \pm 1.9$ & $17.2 \pm 2.7$ \\
\hline Latency, correct responses & $0.86 \pm 0.04$ & $0.88 \pm 0.05$ & $0.87 \pm 0.04$ & $0.97 \pm 0.05$ & $0.89 \pm 0.03$ & $1.03 \pm 0.08$ \\
\hline
\end{tabular}

The table shows \% omissions, total perseverative responses per session, and latencies in seconds. All values are shown as mean $\pm \mathrm{SEM}$.

Table 3 Performance Parameters of Sham Control and Habenula-Lesioned Animals after a Treatment with Either Saline or Amphetamine $(0.2 \mathrm{mg} / \mathrm{kg})$

\begin{tabular}{lrrrr}
\hline & \multicolumn{2}{c}{ Sham } & & Lesioned \\
\cline { 2 - 4 } Parameters & Saline & Amph & Saline & Amph \\
\hline \% Omissions & $14.17 \pm 3.59$ & $14.36 \pm 3.87$ & $10.66 \pm 1.48$ & $14.13 \pm 2.47$ \\
Perseverative responses & $29.77 \pm 4.55$ & $29.22 \pm 7.28$ & $24.42 \pm 4.13$ & $0.91 \pm 0.07$ \\
Latency, correct responses & $0.77 \pm 0.05$ & $0.78 \pm 0.04$ & $1.72 \pm 0.10$ & $1.00 \pm 3.30$ \\
Latency, incorrect responses & $1.95 \pm 0.18$ & $3.67 \pm 0.14$ & $1.66 \pm 0.20$ & $1.49 \pm 0.16$ \\
Latency, pellet & $3.35 \pm 0.63$ & $2.28 \pm 0.47$ & $1.26 \pm 0.09$ \\
\hline
\end{tabular}

The table shows \% omissions, total perseverative responses per session, and latencies in seconds. All values are shown as mean \pm SEM.

Table 4 Performance Parameters of Sham Control and Habenula-Lesioned Animals after Treatment with Either Vehicle or Haloperido (Hal) $(0.01$ or $0.03 \mathrm{mg} / \mathrm{kg})$

\begin{tabular}{|c|c|c|c|c|c|c|}
\hline Parameters & Vehicle & Hal (0.0I mg/kg) & Hal (0.03 mg/kg) & Vehicle & Hal (0.01 mg/kg) & Hal $(0.03 \mathrm{mg} / \mathrm{kg})$ \\
\hline Perseverative responses & $15.77 \pm 1.80$ & $23.00 \pm 4.67$ & $6.22 \pm 2.98$ & $19.71 \pm 3.96$ & $17.28 \pm 2.30$ & $6.42 \pm 1.64$ \\
\hline Latency, correct responses & $1.12 \pm 0.20$ & $0.82 \pm 0.03$ & $0.67 \pm 0.15$ & $1.24 \pm 0.16$ & $1.04 \pm 0.10$ & $1.10 \pm 0.16$ \\
\hline
\end{tabular}

The table shows \% omissions, total perseverative responses per session, and latencies in seconds. All values are shown as mean $\pm \mathrm{SEM}$.

\section{Perseverative Responses}

Effects of bilateral habenula lesions on drug-free performance. As for response omissions, there was no effect of lesion group and no lesion group $\times$ trial block interaction. Two-factor ANOVA showed a significant effect of trial block $(\mathrm{F}(2,28)=3.74, p<0.05)$, but no effect of lesion group $(\mathrm{F}(1,14)=0.005 ; p>0.1)$ and no interaction of these factors $(\mathrm{F}(2,28)=0.005 ; p>0.1)($ Table 2$)$.

Effects of D-amphetamine treatment. Lesion group exerted no significant effect on the mean number of perseverative responses $(F(1,14)=2.2 ; p>0.1)$. There was also no effect of drug treatment $(\mathrm{F}(1,14)=1.64 ; p>0.1)$ and no significant interaction of lesion group $\times$ drug treatment $(F(1,14)=1.3$; $p>0.1$ ) (Table 3).

Effects of haloperidol treatment. There was no significant effect of lesion group on the mean number of perseverative responses $(\mathrm{F}(1,14)=0.02 ; p>0.1)$. However, there was a significant effect of drug treatment $(\mathrm{F}(2,28)=14.3$; $p<0.0001)$ reflecting a reduction of perseverative responses at the higher dose. There was no significant interaction of lesion group $\times$ drug treatment $(\mathrm{F}(2,28)=1.56 ; p>0.1)$ (Table 4). 


\section{Response Latencies}

Effects of bilateral habenula lesions on drug-free performance. Two-factor ANOVA on latencies of correct responses showed a significant effect of trial block $(F(2,28)=5.96$; $p<0.01)$, no effect of lesion group $(\mathrm{F}(1,14)=1.96 ; p>0.1)$ and no significant interaction of these factors $(\mathrm{F}(2,28)=3.23$; $p>0.05)$. The significant effect of trial block reflects a trend for latencies to become slightly longer in the later trial blocks. Two-factor ANOVA on latencies of incorrect responses, in contrast, showed a significant effect of lesion group $(\mathrm{F}(1,14)=10.3 ; p<0.01)$. There was no effect of trial block $(\mathrm{F}(2,28)=2.76 ; p>0.05)$ and no interaction of the factors $(\mathrm{F}(2,28)=0.25 ; p>0.1)$ (Table 2$)$.

Thus, the main conclusion that can be drawn with concern to response latencies is that habenula-lesioned animals had shorter latencies on incorrect trials, and that this difference was constant over trial blocks.

Effects of D-amphetamine treatment. Lesion group exerted no significant effect on the mean latency of correct responses $(F(1,14)=0.9 ; p>0.1)$. Neither was there a significant effect of drug treatment $(\mathrm{F}(1,14)=2.35 ; p>0.1)$ nor a significant interaction of lesion group $\times$ drug treatment $(\mathrm{F}(1,14)=3.65 ; p>0.05)$ (Table 3$)$. There was no significant effect of lesion on the mean latency of incorrect responses $(\mathrm{F}(1,14)=1.22 ; p>0.1)$. However, there was an effect of drug treatment $(\mathrm{F}(1,14)=5 ; p<0.05)$, but no significant interaction of lesion group $\times$ drug treatment $(\mathrm{F}(1,14)=0.05 ; p>0.1)$ (Table 3$)$.

Effects of haloperidol treatment. The analysis showed no significant effect of lesion group on the mean reaction time of correct responses $(\mathrm{F}(1,14)=3.18 ; p>0.05)$. There was no effect of drug treatment $(\mathrm{F}(2,28)=3.03 ; p>0.05)$ and no significant interaction of lesion group $\times$ drug treatment $(\mathrm{F}(2,28)=0.74 ; p>0.1)$. Lesion group exerted no significant effect on the mean latency of incorrect responses $(\mathrm{F}(1,14)=0.004 ; p>0.1)$. There was no effect of drug treatment $(\mathrm{F}(2,28)=0.5 ; p>0.1)$ and no significant interaction of lesion group $\times$ drug treatment $(\mathrm{F}(2,28)=1.9$; $p>0.1$ ) (Table 4).

\section{Latency to Collect the Food Pellet}

Effects of bilateral habenula lesions on drug-free performance. According to two-factor ANOVA habenula-lesioned animals showed significantly shorter latencies to collect the food pellet $(F(1,14)=26.24$; $p<0.001)$. There was also a significant effect of trial block $(\mathrm{F} 2,28)=3.51 ; p<0.05)$, but no significant interaction of these factors $F(2,28)=0.52$; $p>0.5$ ) (Table 2).

Thus, habenula-lesioned animals collected the food pellet with a shorter latency than controls, an effect which was constant over trial blocks.

Effects of D-amphetamine treatment. Lesion group had a significant effect on the mean latency to collect the pellet $(\mathrm{F}(1,14)=11.8 ; p<0.01)$, but there was no effect of drug treatment $(\mathrm{F}(1,14)=1.98 ; p>0.1)$ and no significant interaction of lesion group $\times$ drug treatment $(\mathrm{F}(1,14)=0.41$; $p>0.1$ ) (Table 3).

Effects of haloperidol treatment. There was no significant effect of lesion group $(\mathrm{F}(1,14)=1.12 ; p>0.1)$, no significant effect of drug treatment $(\mathrm{F}(2,28)=1.45 ; p>0.1)$ and no significant interaction of lesion group $\times$ drug treatment $(\mathrm{F}(2,28)=0.03 ; p>0.1)$ on the mean latency to collect the food pellet (Table 4).

\section{Histology}

As illustrated in Figure 4, habenula lesions destroyed a large proportion of both medial and lateral habenula without causing significant damage to neighboring structures. Only animals with such lesions were included in the analysis of behavioral effects.

\section{ChAT Assay}

As shown in Table 5, rats with lesions of the habenula had a marked reduction, by $78 \%$, of ChAT activity of the IPN, compared to the sham-operated animals. This result is consistent with those of previous neurochemical studies (Villani et al, 1983; Contestabile et al, 1987; Eckenrode et al, 1987) and indicates marked degeneration of the habenulointerpeduncular cholinergic tract.

\section{DISCUSSION}

The aim of the present studies was to examine whether bilateral lesions of the habenula would cause deficits in performing the 5-CSRTT, a task in which attention plays an
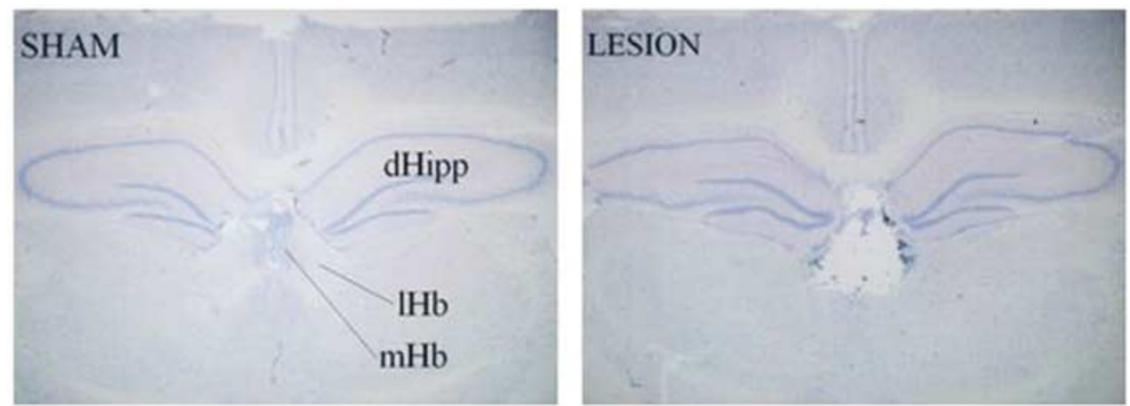

Figure 4 Typical sections through the habenula region of a sham-operated rat and a bilateral habenula-lesioned rat. Only animals with similar lesions, showing large destruction of the habenula without significant damage to neighboring structures, were included in the analysis of behavioral effects. mHb, medial habenula; $\Vdash \mathrm{Hb}$, lateral habenula; dHipp, dorsal hippocampus. 
Table 5 ChAT (mean \pm SEM; $\mu$ mol/g wet wt./h) in Homogenates of IPN from Sham- and Habenula-Lesioned Animals

\begin{tabular}{ll}
\hline Group & ChAT ( $\boldsymbol{\mu m o l} / \mathbf{g}$ wet wt./h) \\
\hline Sham & $83.5 \pm 6.6$ \\
Lesioned & $18.5 \pm 9.6(22.1 \pm 11.5 \%)^{* * *}$ \\
\hline
\end{tabular}

Values within parentheses are expressed as percentage of the sham value. *** $p<0.00$ I vs sham-operated (two-tailed $t$-test).

important role. The results clearly showed that multiple deficits resulted from such lesions, and to our knowledge are the first data to demonstrate a role for the habenula in the performance of a test of attention.

The major behavioral consequences after the habenula lesion in the 5-CSRTT are a marked increase of the number of premature responses and alterations in accuracy. Interestingly, the deficits observed during the task can be distinguished in terms of their time course. At one extreme increased premature responses appeared immediately upon reinstating testing after the lesion, and thereafter declined in magnitude. At the other extreme choice accuracy was not significantly altered in the first test sessions upon reinstating testing, and became progressively worse in the habenula-lesioned animals as testing progressed. Falling between these two extremes were shortened latencies for incorrect responses and for retrieving the food pellet in lesioned animals, which appeared already in the first block of postoperative test sessions and then remained stable. Given that the habenula consists of 15 subnuclei (Andres et al, 1999; Geisler et al, 2003), it is understandable that alterations with different properties exist. Elucidating the circuits involved in these various alterations will clearly require further experiments. Here, we restrict ourselves to considering the possible role of elevated dopamine in the changes of premature responses and choice accuracy.

With regard to the increase of premature responses occurring shortly after the lesion, one possible behavioral explanation is that this increase reflects an impaired ability to focus attention only on the most relevant aspect of the task, namely the occurrence of a stimulus light. Instead, the stimulus recesses themselves that have become associated with reward during training elicit an inappropriate level of responding. As only a slight, short-lasting increase of locomotor activity is present in habenula-lesioned animals (Lecourtier et al, 2004), it is unlikely that the increase of premature responding is merely a reflection of generalized hyperactivity. Moreover, it seems unlikely that the increased premature responding could be explained by a motor effect of the lesion to nonspecifically facilitate responding in the stimulus alcoves, since there was no increase at all of perseverative responding caused by the lesion. It is currently difficult to conclude whether the increase in premature responses in habenula-lesioned rats corresponds to a particular aspect of the behavior of patients with schizophrenia. Premature responding has been considered to represent some aspect of impulsivity (Winstanley $e t$ al, 2004 ), which is a troubling symptom of a proportion of schizophrenics (Hoptman et al, 2002; Spivak et al, 1997, 2003). Future pharmacological characterization of this behavior in rats and of the various measures of impulsivity in man will be invaluable in deciding how well these behaviors correspond to each other.

It has been emphasized (Robbins, 1998; Chudasama et al, 2003) that the ability to inhibit inappropriate responses in a complex situation such as the 5-CSRTT is an important aspect of executive control, probably involving frontal cortical regions (Duncan and Owen, 2000). One candidate as a likely neural mechanism responsible for this effect, which is consistent with previous findings and the present data, is increased release of dopamine in mesolimbic or mesocortical dopaminergic pathways. The habenula exerts an inhibitory influence on dopaminergic cells of the ventral tegmentum (Christoph et al, 1986). Correspondingly, acute interruption of impulse flow in the habenula increases the turnover of dopamine in mesolimbic and mesocortical regions (Nishikawa et al, 1986), while chronic lesions of habenula produce a long-lasting increase of dopamine turnover selectively in frontal cortex (Lisoprawski et al, 1980). Cole and Robbins (1989) showed that the marked increase of premature responding evoked by amphetamine was greatly attenuated by 6-hydroxydopamine-induced lesions of the nucleus accumbens that damage mesolimbic dopamine terminals and mesocortical dopamine axons running through that region. This evidence is consistent with the view that lesions of the habenula result in increased mesolimbic/mesocortical dopamine release, which then causes the observed increase in premature responding. The effects of the dopamine antagonist, haloperidol, observed here are consistent with this view, as the effect of haloperidol on premature responding was to reduce it. The fact that haloperidol clearly reduced premature responding in nonlesioned animals suggests that there is some dopamine release in control animals that contributes to premature responding. For comparison, one previous study reported no significant effect of haloperidol on premature responding (Carli and Samanin, 1992) without showing the absolute data. Conceivably the possibility of obtaining a reduction was limited by a 'floor effect'. A further study showed a tendency to reduced premature responses after the dopamine D2 antagonist, sulpiride, and a significant reduction after the dopamine D1 antagonist SCH23390 (Harrison et al, 1997). It is possible that both a reduction in the secondary-reinforcing properties of the stimulus alcoves and some motor disturbance contribute to these effects of haloperidol. However, arguing against any pronounced motor disturbance, response latencies and latencies to collect food pellets were not lengthened. In agreement with previous studies in intact animals (Cole and Robbins, 1987, 1989), amphetamine, an enhancer of dopamine release, increased premature responses in sham-operated animals. The effect of amphetamine does not seem to be due to any motor effect that generally increases nose-poking into the stimulus alcoves since perseverative responding was completely unaltered.

Since global depletion of brain serotonin by 5,7 dihydroxytryptamine increases premature responding in this task (Harrison et al, 1997; Winstanley et al, 2004), it should be considered whether increased premature responding after amphetamine or habenula lesions might be due to reduced serotonin release. With regard to amphetamine, this seems unlikely since the effect of amphetamine on 
serotonin release is facilitation, albeit at doses a 100 -fold higher than those that affect catecholamine release (Rothman et al, 2001). Moreover, no effect of serotonin depletion on increased premature responses provoked by low amphetamine doses was observed (Harrison et al, 1997). Regarding the habenula lesion effect, the majority of studies indicate an inhibitory influence of habenula activity on serotonergic neurons (Wang and Aghajanian, 1977; Speciale et al, 1980; Reisine et al, 1982), such that the effect of lesions would be elevated serotonin release, which would be predicted to decrease premature responding.

In contrast to premature responding, choice accuracy was not significantly altered shortly after habenula lesion, but was impaired at later times. Whereas a degree of behavioral recovery often occurs after other brain lesions, we are not aware of another example of a progressive deficit after a restricted brain lesion in an adult animal. This different time course compared to that of the elevation of premature responding suggests that different neural mechanisms are involved. Also, unlike premature responding, this lesioninduced deficit was not ameliorated at all by haloperidol. Neither was choice accuracy worsened by D-amphetamine, in agreement with the effects of comparable doses in several previous studies (Cole and Robbins, 1987, 1989; Muir et al, 1995; Harrison et al, 1997). Theoretically, sensitization of dopaminergic transmission by prolonged hyperactivity (Vanderschuren et al, 1999, 2000), until it exceeded a threshold level, could be a possible explanation of the time course of impairment of choice accuracy. However, the lack of effects of haloperidol and D-amphetamine in doses that exerted effects on premature responding in the same experiment indicates that elevated dopaminergic transmission does not appear to play a role in this impairment. Alternative explanations include the possibility of some progressive neural degeneration after habenula lesion. While we have not observed any obvious neural degeneration, further studies are necessary to examine this possibility in detail. Finally, there remains the possibility of a mechanism of the type proposed by one of us (Kelly, 1998), according to which habenula dysfunction results in a progressive accumulation of delusional memories, so that cognitive functions are progressively disturbed by the accumulation of wrongly strengthened synaptic connections that are the neural substrate of these delusional memories. The progressive deficit in choice accuracy is consistent with such a mechanism, but of course does not prove it. Further, we can reasonably eliminate the possibility that this lateoccurring impairment of choice accuracy arises from an impairment of visual ability, since in a different cognitive task, the Morris water-maze, rats with a lesion of the habenula performed the visible platform condition of the test as well as sham-operated controls, although they were impaired in finding the hidden platform (Lecourtier et al, 2004).

The effects of habenula lesions observed here in the 5CSRTT do not appear to be caused by a lesion-induced increase in food motivation. A consistent finding from several laboratories is that when food motivation is reduced by prefeeding, there is an increase of 'percentage omissions', the percentage of stimuli that elicit no response (Carli and Samanin, 1992; Harrison et al, 1997; Grottick and Higgins, 2000, 2002; Bizarro and Stolerman, 2003). In none of these studies was choice accuracy altered by manipulating food motivation. In the present study, the lesion resulted in a delayed reduction in choice accuracy and no alteration of percentage omissions with the exception of an overall lesion effect in the haloperidol experiment. This latter result is difficult to explain currently. Thus, the lesioninduced changes cannot readily be accounted for by an alteration of motivation. Moreover, previous lesion evidence suggests that the habenula is not involved in food intake (Mok et al, 1973).

Even if attention deficits in schizophrenia are due to habenula dysfunction, it is not necessarily the case that animals with habenula lesions are a model of attentional deficit in schizophrenia in the pharmacological sense that chronic treatment with neuroleptics is expected to improve measures such as choice accuracy. It may be, for example, that the marked effect of neuroleptics on activity of the habenula (McCulloch, 1982; Palacios and Wiederhold, 1985; Room et al, 1991) is necessary for their improvement in attentional performance when administered chronically (Orzack et al, 1967; Spohn and Strauss, 1989). In this case, animals with complete habenula lesions would be a model of patients who are nonresponders to neuroleptics, in respect to their attentional choice accuracy deficit. Moreover, although in many studies of patients with schizophrenia attentional performance was improved by chronic neuroleptic treatment, there are other studies in which such treatment had no significant beneficial effect (Allen et al, 1997; Liu et al, 2000; review: Blyler and Gold, 2000). Factors contributing to such different outcomes may include the exact nature of the test, concomitant medication with the anticholinergic agent benztropine, sample size, and duration of the medication-free period before baseline assessment. It is beyond the scope of this discussion to consider all the possible factors that may contribute to such different outcomes. However, consistent with a progressive loss of the substrate for beneficial effects of neuroleptic treatment on attention, it is interesting that better effects were found in younger patients compared to older patients (Harvey et $\mathrm{al}, 2003 \mathrm{a}, \mathrm{b})$, and no positive effects were found in a patient population that comprised a high proportion of patients who were neuroleptic nonresponders with respect to other symptoms (Epstein et al, 1996).

The present results are relevant to the hypothesis that habenula dysfunction is involved in the cognitive symptoms of schizophrenia. This hypothesis is based on several lines of evidence. For example, excessive calcification of the habenula or of the epithalamus, comprising the habenular nuclei plus the pineal organ, is observed in schizophrenia patients (Sandyk, 1992; Caputo et al, 1998). Moreover, chronic stimulant exposure selectively damages the lateral habenula and its fasciculus retroflexus output pathway in experimental animals (Ellison, 1992), and in man can lead to a schizophrenia-like state (Sato et al, 1983; Satel and Edell, 1991). In examining the prediction that habenula lesions would therefore cause schizophrenia-like symptoms in rats, we recently found that such lesions produced cognitive disturbance in the Morris water-maze spatial reference memory task (Lecourtier et al, 2004) that is thought to be analogous to declarative memory (O'Keefe and Nadel, 1978), which is impaired in schizophrenia (Perry et al, 2000; Cirillo and Seidman, 2003). In the same series of 
studies, we found no deficit of PPI of a startle response, a phenomenon that is impaired in schizophrenia patients (Braff et al, 1978, 1992, 1999). Interestingly, however, a deficit in PPI in habenula-lesioned mice has recently been described, which was not initially present but which appeared after the experience of fear-conditioning (Heldt and Ressler, 2004). Similar to the deficit in choice accuracy observed here, this deficit resulting from habenula lesion is therefore experience-dependent.

In the present experiments, the prediction that habenula lesions would cause schizophrenia-like symptoms was further tested by examining performance in a test of attentional mechanisms, since numerous studies have emphasized that disturbances of attention are common in schizophrenia (Bleuler, 1950; McGhie and Chapman, 1961; Chen and Faraone, 2000; Barr, 2001). Our results showed that habenula lesions caused multiple deficits in an attention task that is modeled after the clinically used continuous performance test of attention (Chudasama and Robbins, 2004), in which schizophrenia patients are impaired. Thus, a prediction of the hypothesis that habenula lesions contribute to cognitive impairments in schizophrenia was confirmed, so that the hypothesis withstood this challenge. The results add to accumulating evidence that the hypothesis that habenula dysfunction contributes to cognitive impairment in schizophrenia deserves further consideration.

\section{ACKNOWLEDGEMENTS}

We thank Dr John F Cryan for critical reading of the manuscript and helpful comments. This work was supported by Novartis Pharma Ltd.

\section{REFERENCES}

Allen DN, Gilbertson MW, van Kammen DP, Kelley ME, Gurklis Jr JA, Barry EJ (1997). Chronic haloperidol treatment does not affect structure of attention in schizophrenia. Schizophr Res 25: 53-61.

Amat J, Sparks PD, Matus-Amat P, Griggs J, Watkins LR, Maier SF (2001). The role of the habenular complex in the elevation of dorsal raphe nucleus serotonin and the changes in the behavioral responses produced by uncontrollable stress. Brain Res 917: $118-126$.

Andres KH, von During M, Veh RW (1999). Subnuclear organization of the rat habenular complexes. J Comp Neurol 407: $130-150$.

Barr WB (2001). Schizophrenia and attention deficit disorder. Two complex disorders of attention. Ann NY Acad Sci 931: 239-250.

Bizarro L, Stolerman IP (2003). Attentional effects of nicotine and amphetamine in rats at different levels of motivation. Psychopharmacology 170: 271-277.

Bleuler E (1950). Dementia praecox or the group of schizophrenias (English translation; Zinkin, J). International Universities Press: New York. (original, 1911).

Blyler RB, Gold JM (2000). Cognitive effects of typical antipsychotic treatment: another look. In: Sharma T, Harvey P (eds). Cognition in Schizophrenia: Impairments, Importance and Treatment Strategies. Oxford University Press: Oxford. pp 241-265.

Braff D, Stone C, Callaway E, Geyer M, Glick I, Bali L (1978). Prestimulus effects on human startle reflex in normals and schizophrenics. Psychophysiology 15: 339-343.
Braff DL, Grillon C, Geyer MA (1992). Gating and habituation of the startle reflex in schizophrenic patients. Arch Gen Psychiatry 49: 206-215.

Braff DL, Swerdlow NR, Geyer MA (1999). Symptom correlates of prepulse inhibition deficits in male schizophrenic patients. Am J Psychiatry 156: 596-602.

Cadenhead KS, Braff DL (2000). Information processing and attention in schizophrenia: clinical and functional correlates and treatment of cognitive impairment. In: Sharma T, Harvey $\mathrm{P}$ (eds). Cognition in Schizophrenia: Impairments, Importance and Treatment Strategies. Oxford University Press: Oxford. pp 92-106.

Caputo A, Ghiringhelli L, Dieci M, Giobbio GM, Tenconi F, Ferrari L et al (1998). Epithalamus calcification in schizophrenia. Eur Arch Psychiatry Clin Neurosc 248: 272-277.

Carli M, Robbins TW, Evenden JL, Everitt BJ (1983). Effects of lesions to ascending noradrenergic neurons on performance of a 5-choice serial reaction task in rats; implications for theories of dorsal noradrenergic bundle function based on selective attention and arousal. Behav Brain Res 9: 361-380.

Carli M, Samanin R (1992). Serotonin2 receptor agonists and serotonergic anorectic drugs affect rats' performance differently in a five-choice serial reaction time task. Psychopharmacology 106: 228-234.

Chen WJ, Faraone SV (2000). Sustained attention deficits as markers of genetic susceptibility to schizophrenia. Am J Med Genet 97: 52-57.

Christoph GR, Leonzio RJ, Wilcox KS (1986). Stimulation of the lateral habenula inhibits dopamine-containing neurons in the substantia nigra and ventral tegmental area of the rat. J Neurosci 6: 613-619.

Chudasama Y, Passetti F, Rhodes SE, Lopian D, Desai A, Robbins TW (2003). Dissociable aspects of performance on the 5-choice serial reaction time task following lesions of the dorsal anterior cingulate, infralimbic and orbitofrontal cortex in the rat: differential effects on selectivity, impulsivity and compulsivity. Behav Brain Res 146: 105-119.

Chudasama Y, Robbins TW (2004). Psychopharmacological approaches to modulating attention in the five-choice serial reaction time task: implications for schizophrenia. Psychopharmacology 174: 86-98.

Cirillo MA, Seidman LJ (2003). Verbal declarative memory dysfunction in schizophrenia: from clinical assessment to genetics and brain mechanisms. Neuropsychol Rev 13: 43-77.

Cohen SR, Melzack R (1993). The habenula and pain: repeated electrical stimulation produces prolonged analgesia but lesions have no effect on formalin pain or morphine analgesia. Behav Brain Res 54: 171-178.

Cole BJ, Robbins TW (1987). Amphetamine impairs the discriminative performance of rats with dorsal noradrenergic bundle lesions on a 5-choice serial reaction time task: new evidence for central dopaminergic-noradrenergic interactions. Psychopharmacology 91: 458-466.

Cole BJ, Robbins TW (1989). Effect of 6-hydroxydopamine lesions of the nucleus accumbens septi on performance of a 5-choice serial reaction time task in rats: implication for theories of selective attention and arousal. Behav Brain Res 33: 165-179.

Contestabile A, Villani L, Fasolo A, Franzoni MF, Gribaudo L, Oktedalen O et al (1987). Topography of cholinergic and substance $P$ pathways in the habenulo-interpeduncular system of the rat. An immunocytochemical and microchemical approach. Neuroscience 21: 253-270.

Corfas G, Roy K, Buxbaum JD (2004). Neuregulin 1-erbB signaling and the molecular/cellular basis of schizophrenia. Nat Neurosci 7: $575-580$.

Corodimas KP, Rosenblatt JS, Canfield ME, Morrell JI (1993). Neurons in the lateral subdivision of the habenular complex 
mediate the hormonal onset of maternal behavior in rats. Behav Neurosci 107: 827-843.

Duncan J, Owen AM (2000). Common regions of the human frontal lobe recruited by diverse cognitive demands. Trends Neurosci 23: 475-483.

Eckenrode TC, Barr GA, Battisti WP, Murray M (1987). Acetylcholine in the interpeduncular nucleus of the rat: normal distribution and effects of deafferentation. Brain Res 418: 273-286.

Ellison G (1992). Continuous amphetamine and cocaine have similar neurotoxic effects in lateral habenular nucleus and fasciculus retroflexus. Brain Res 598: 353-356.

Ellison G (1994). Stimulant-induced psychosis, the dopamine theory of schizophrenia, and the habenula. Brain Res Rev 19: 223-239.

Epstein JI, Keefe RS, Roitman SL, Harvey PD, Mohs RC (1996). Impact of neuroleptic medications on continuous performance test measures in schizophrenia. Biol Psychiatry 39: 902-905.

Felton TM, Linton L, Rosenblatt JS, Morrell JI (1998). Intact neurons of the lateral habenular nucleus are necessary for the nonhormonal, pup-mediated display of maternal behavior in sensitized virgin female rats. Behav Neurosci 112: 1458-1465.

Finkelstein JR, Cannon TD, Gur RE, Gur RC, Moberg P (1997). Attentional dysfunctions in neuroleptic-naive and neurolepticwithdrawn schizophrenic patients and their siblings. J Abnorm Psychol 106: 203-212.

Fonnum F (1975). A rapid radiochemical method for the determination of choline acetyltransferase. J Neurochem 24: 407-409.

Geisler S, Andres KH, Veh RW (2003). Morphologic and cytochemical criteria for the identification and delineation of individual subnuclei within the lateral habenular complex of the rat. J Comp Neurol 458: 78-97.

Grottick AJ, Higgins GA (2000). Effect of subtype selective nicotinic compounds on attention as assessed by the five-choice serial reaction time task. Behav Brain Res 117: 197-208.

Grottick AJ, Higgins GA (2002). Assessing a vigilance decrement in aged rats: effects of pre-feeding, task manipulation, and psychostimulants. Psychopharmacology 164: 33-41.

Harrison AA, Everitt BJ, Robbins TW (1997). Central 5-HT depletion enhances impulsive responding without affecting the accuracy of attentional performance: interactions with dopaminergic mechanisms. Psychopharmacology 133: 329-342.

Harvey PD, Green MF, McGurk SR, Meltzer HY (2003a). Changes in cognitive functioning with risperidone and olanzapine treatment: a large-scale, double-blind, randomized study. Psychopharmacology 169: 404-411.

Harvey PD, Napolitano JA, Mao L, Gharabawi G (2003b). Comparative effects of risperidone and olanzapine on cognition in elderly patients with schizophrenia or schizoaffective disorder. Int J Geriatr Psychiatry 18: 820-829.

Haun F, Eckenrode TC, Murray M (1992). Habenula and thalamus cell transplants restore normal sleep behaviors disrupted by denervation of the interpeduncular nucleus. J Neurosci 12: $3282-3290$.

Heldt SA, Ressler KJ (2004). The habenula complex mediates experience-dependent regulation of monoamine systems. $A b$ stract of the International Behavioral Neuroscience Society Meeting, Key-West, FL.

Hoptman MJ, Volavka J, Johnson G, Weiss E, Bilder RM, Lim KO (2002). Frontal white matter microstructure, aggression, and impulsivity in men with schizophrenia: a preliminary study. Biol Psychiatry 52: 9-14.

Kelly PH (1998). Defective inhibition of dream event memory formation: a hypothesized mechanism in the onset and progression of symptoms of schizophrenia. Brain Res Bull 46: 189-197.
Kelly PH, Moore KE (1978). Decrease of neocortical choline acetyltransferase after lesion of the globus pallidus in the rat. Exp Neurol 61: 479-484.

Kraepelin E (1971). Dementia Praecox, (translated by Barclay E, Barclay S) Churchill Livingstone: New York. (original work published in 1919).

Kurumaji A, Umino A, Tanami M, Ito A, Asakawa M, Nishikawa T (2003). Distribution of anxiogenic-induced c-Fos in the forebrain regions of developing rats. J Neural Transm 110: 1161-1168.

Lecourtier L, Neijt HC, Kelly PH (2004). Habenula lesions result in impaired cognitive performance in rats: implications for schizophrenia. Eur J Neurosci 19: 2551-2560.

Lisoprawski A, Herve D, Blanc G, Glowinski J, Tassin JP (1980). Selective activation of the mesocortico-frontal dopaminergic neurons induced by lesion of the habenula in the rat. Brain Res 183: 229-234.

Liu SK, Chen WJ, Chang CJ, Lin HN (2000). Effects of atypical neuroleptics on sustained attention deficits in schizophrenia: a trial of risperidone versus haloperidol. Neuropsychopharmacology 22: 311-319.

McCulloch J (1982). Mapping functional alterations in the CNS with $\left[{ }^{14} \mathrm{C}\right]$ deoxyglucose. In: Iversen LL, Iversen SD, Snyder SH (eds). Handbook of Psychopharmacology. Plenum Press: New York and London. pp 321-410.

McGhie A, Chapman J (1961). Disorders of attention and perception in early schizophrenia. $\mathrm{Br} J$ Med Psychol 34: 103-116.

Mok AC, Box BM, Mogenson GJ (1973). The effect of ablating the habenular nucleus of rats recovered from lesions of the lateral hypothalamus. Physiol Behav 11: 577-579.

Muir JL, Everitt BJ, Robbins TW (1995). Reversal of visual attentional dysfunction following lesions of the cholinergic basal forebrain by physostigmine and nicotine but not by the $5-\mathrm{HT}_{3}$ receptor antagonist, ondansetron. Psychopharmacology 118: 82-92.

Murphy CA, DiCamillo AM, Haun F, Murray M (1996). Lesion of the habenular efferent pathway produces anxiety and locomotor hyperactivity in rats: a comparison of the effects of neonatal and adult lesions. Behav Brain Res 81: 43-52.

Nestor PG, O'Donnell BF (1998). The mind adrift: attentional dysregulation in schizophrenia. In: Parasuraman $\mathrm{R}$ (ed). The Attentive Brain. MIT Press: Cambridge, MA. pp 527-546.

Nieuwenstein MR, Aleman A, de Haan EH (2001). Relationship between symptom dimensions and neurocognitive functioning in schizophrenia: a meta-analysis of WCST and CPT studies. J Psychiatr Res 35: 119-125.

Nishikawa T, Fage D, Scatton B (1986). Evidence for, and nature of, the tonic inhibitory influence of habenulointerpeduncular pathways upon cerebral dopaminergic transmission in the rat. Brain Res 373: 324-336.

O'Keefe J, Nadel L (1978). The Hippocampus as a Cognitive Map. Oxford University Press: New York.

Orzack MH, Kornetsky C (1966). Attention dysfunction in chronic schizophrenia. Arch Gen Psychiat 14: 323-326.

Orzack MH, Kornetsky C, Freeman H (1967). The effects of daily administration of carphenazine on attention in the schizophrenic patient. Psychopharmacologia 11: 31-38.

Palacios JM, Wiederhold KH (1985). Dopamine D2 receptor agents, but not dopamine D1, modify brain glucose metabolism. Brain Res 327: 390-394.

Pellegrino LJ, Pellegrino AS, Cushman AJ (1979). A Stereotaxic Atlas of the Rat Brain, 2nd edn. Plenum Press: New York.

Perry W, Light GA, Davis H, Braff DL (2000). Schizophrenia patients demonstrate a dissociation on declarative and nondeclarative memory tests. Schizophr Res 46: 167-174.

Reisine TD, Soubrie P, Artaud F, Glowinski J (1982). Involvement of lateral habenula-dorsal raphe neurons in the differential 
regulation of striatal and nigral serotonergic transmission in cats. J Neurosci 2: 1062-1071.

Robbins TW (1998). Dissociating executive functions of the prefrontal cortex. In: Roberts AC, Robbins TW, Weiskrantz L (eds). The Prefrontal Cortex. Executive and Cognitive Functions. Oxford University Press: Oxford. pp 117-130.

Robbins TW (2002). The 5-choice serial reaction time task: behavioural pharmacology and functional neurochemistry. Psychopharmacology 163: 362-380.

Room P, Tielemans AJ, De Boer T, Van Delft AM, Tonnaer JA (1991). The effect of the potential antipsychotic ORG 5222 on local cerebral glucose utilization in freely moving rats. Eur $J$ Pharmacol 205: 233-240.

Rothman RB, Baumann MH, Dersch CM, Romero DV, Rice KC, Carroll FI et al (2001). Amphetamine-type central nervous system stimulants release norepinephrine more potently than they release dopamine and serotonin. Synapse 39: 32-41.

Sandyk R (1991). Relevance of the habenular complex to neuropsychiatry: a review and hypothesis. Int J Neurosci 61: 189-219.

Sandyk R (1992). Pineal and habenula calcification in schizophrenia. Int J Neurosci 67: 19-30.

Satel SL, Edell WS (1991). Cocaine-induced paranoia and psychosis proneness. Am J Psychiatry 148: 1708-1711.

Sato M, Chen CC, Akiyama K, Otsuki S (1983). Acute exacerbation of paranoid psychotic state after long-term abstinence in patients with previous methamphetamine psychosis. Biol Psychiatry 18: 429-440.

Sica AL, Greenberg HE, Scharf SM, Ruggiero DA (2000). Chronicintermittent hypoxia induces immediate early gene expression in the midline thalamus and epithalamus. Brain Res 883: 224-228.

Speciale SG, Neckers LM, Wyatt RJ (1980). Habenular modulation of raphe indoleamine metabolism. Life Sci 27: 2367-2372.

Spivak B, Mester R, Wittenberg N, Maman Z, Weizman A (1997). Reduction of aggressiveness and impulsiveness during clozapine treatment in chronic neuroleptic-resistant schizophrenic patients. Clin Neuropharmacol 20: 442-446.

Spivak B, Shabash E, Sheitman B, Weizman A, Mester R (2003). The effects of clozapine versus haloperidol on measures of impulsive aggression and suicidality in chronic schizophrenia patients: an open, nonrandomized, 6-month study. J Clin Psychiatry 64: 755-760.

Spohn HE, Strauss ME (1989). Relation of neuroleptic and anticholinergic medication to cognitive functions in schizophrenia. J Abnorm Psychol 98: 367-380.

Stefansson H, Sarginson J, Kong A, Yates P, Steinthorsdottir V, Gudfinnsson E et al (2003). Association of neuregulin 1 with schizophrenia confirmed in a Scottish population. Am J Hum Genet 72: 83-87.
Stefansson H, Sigurdsson E, Steinthorsdottir V, Bjornsdottir S, Sigmundsson T, Ghosh S et al (2002). Neuregulin 1 and susceptibility to schizophrenia. Am J Hum Genet 71: 877-892.

Steiner H, Blum M, Kitai ST, Fedi P (1999). Differential expression of ErbB3 and ErbB4 neuregulin receptors in dopamine neurons and forebrain areas of the adult rat. Exp Neurol 159: 494-503.

Sutherland RJ (1982). The dorsal diencephalic conduction system: a review of the anatomy and functions of the habenular complex. Neurosci Biobehav Rev 6: 1-13.

Sutherland RJ, Nakajima S (1981). Self-stimulation of the habenular complex in the rat. J Comp Physiol Psychol 95: 781-791.

Thornton EW, Evans JC (1982). The role of habenular nuclei in the selection of behavioral strategies. Physiol Psychol 10: 361-367.

Valjakka A, Vartiainen J, Tuomisto L, Tuomisto JT, Olkkonen H, Airaksinen MM (1998). The fasciculus retroflexus controls the integrity of REM sleep by supporting the generation of hippocampal theta rhythm and rapid eye movements in rats. Brain Res Bull 47: 171-184.

Vanderschuren LJ, Kalivas PW (2000). Alterations in dopaminergic and glutamatergic transmission in the induction and expression of behavioral sensitization: a critical review of preclinical studies. Psychopharmacology 151: 99-120.

Vanderschuren LJ, Schoffelmeer AN, Mulder AH, De Vries T] (1999). Dopaminergic mechanisms mediating the longterm expression of locomotor sensitization following preexposure to morphine or amphetamine. Psychopharmacology 143: 244-253.

Villani L, Contestabile A, Fonnum F (1983). Autoradiographic labeling of the cholinergic habenulo-interpeduncular projection. Neurosci Lett 42: 261-266.

Wang RY, Aghajanian GK (1977). Physiological evidence for habenula as major link between forebrain and midbrain raphe. Science 197: 89-91.

Whishaw IQ, Cioe JD, Previsich N, Kolb B (1977). The variability of the interaural line $v s$ the stability of bregma in rat stereotaxic surgery. Physiol Behav 19: 719-722.

Williams NM, Preece A, Spurlock G, Norton N, Williams HJ, Zammit S et al (2003). Support for genetic variation in neuregulin 1 and susceptibility to schizophrenia. Mol Psychiatry 8: $485-487$.

Winstanley CA, Theobald DE, Dalley JW, Glennon JC, Robbins TW (2004). 5-HT(2A) and 5-HT(2C) receptor antagonists have opposing effects on a measure of impulsivity: interactions with global 5-HT depletion. Psychopharmacology (Electronic publication ahead of print), DOI:10.1007/S00213-004-1884-9.

Yang JZ, Si TM, Ruan Y, Ling YS, Han YH, Wang XL et al (2003). Association study of neuregulin 1 gene with schizophrenia. Mol Psychiatry 8: 706-709. 